\title{
Monitoring Acute Myocardial Infarction Complicated with Cardiogenic Shock - from the Emergency Room to Coronary Care Units
}

\author{
Andreea Barcan ${ }^{1}$, Zsuzsanna Suciu ${ }^{2}$, Emese Rapolti ${ }^{3}$ \\ ${ }^{1}$ Mediaş Municipal Hospital, Romania \\ ${ }^{2}$ Gheorgheni City Hospital, Romania \\ ${ }^{3}$ Cardiovascular Rehabilitation Hospital, Covasna, Romania
}

\begin{abstract}
Cardiogenic shock remains the leading cause of death in patients hospitalized for acute myocardial infarction, despite many advances encountered in the last years in reperfusion, mechanical, and pharmacological therapies addressed to stabilization of the hemodynamic condition of these critical patients. Such patients require immediate initiation of the most effective therapy, as well as a continuous monitoring in the Coronary Care Unit. Novel biomarkers have been shown to improve diagnosis and risk stratification in patients with cardiogenic shock, and their proper use may be especially important for the identification of the critical condition, leading to prompt therapeutic interventions. The aim of this review was to evaluate the current literature data on complex biomarker assessment and monitoring of patients with acute myocardial infarction complicated with cardiogenic shock in the Coronary Care Unit.
\end{abstract}

Keywords: acute myocardial infarction, cardiogenic shock, biomarkers, coronary care unit monitoring

\section{ARTICLE HISTORY}

Received: April 27, 2017

Accepted: May 21, 2017

\section{CORRESPONDENCE}

\section{Zsuzsanna Suciu}

Bul. Lacu Roșu nr. 16

535500 Gheorgheni, Romania

Tel: +40 266364008

E-mail: szoke_zsuzsanna@yahoo.com
Cardiogenic shock (CS) remains the leading cause of death in patients hospitalized for acute myocardial infarction (AMI), occurring in $7 \%$ to $10 \%$ of AMI patients. ${ }^{1-4}$ In-hospital mortality rates for CS complicating AMI are reaching $50 \%$, and short-term prognosis is linked to the severity of hemodynamic disturbances. ${ }^{5}$ Several studies have suggested that short-term mortality in CS ranges between $42 \%$ and $48 \%$, and that most patients will succumb due to multiple organ failure as a consequence of organ hypoperfusion. ${ }^{6-8}$

CS implies a systolic blood pressure lower than 90 mmHg for more than 30 minutes, caused by a severe myocardial dysfunction, leading to systemic hypoperfusion. The clinical signs of CS can vary from decreased diuresis and indicators of peripheral vasoconstriction to altered mental status. ${ }^{9}$

Hemodynamic changes in CS trigger various biochemical pathways due to tissue ischemia, elevated systemic inflammation, cellular apoptosis, neurohormonal activation, and extracellular matrix degradation..$^{13-13}$ CS patients undergo rapid changes in their clinical, biochemical, and hemodynamic status, either due to the disease itself, or secondary to the multitude of therapeutic interventions. The proper determination and use of complex biomarkers 
that illustrate such changes may be highly important for identifying the critical condition, leading to prompt therapeutic interventions, as well as for risk stratification..$^{14}$ Novel biomarkers have been under intensive research in the last years in an attempt to identify predictors for the evolution of this critical disease.

Nevertheless, AMI patients complicated with CS require immediate diagnosis and management that should include a continuous monitoring in the Coronary Care Unit (CCU) besides invasive or noninvasive therapies. A careful monitoring could be helpful for the immediate detection of changes in the clinical, hemodynamic, and biochemical status, resulting in the timely initiation of the appropriate intervention and thus reducing mortality.

The aim of this article was to review the current literature data on complex biomarker assessment and monitoring of patients with AMI complicated with CS in the CCU.

\section{SERUM BIOMARKERS IN AMI COMPLICATED WITH CARDIOGENIC SHOCK}

The most used biomarkers in acute cardiovascular settings include myocardial injury enzymes, parameters that express hemodynamic stress, systemic inflammation markers, as well as other emerging biomarkers such as extracellular matrix degradation indicators or micro-RNAs. These biomarkers can be extremely important in monitoring response to treatment and for risk stratification in critical care conditions, helping to better guide the therapy of acute heart failure patients and leading to improvement in clinical management and outcomes. ${ }^{15,16}$

\section{MARKERS FOR MYOCARDIAL INJURY IN THE EMERGENCY ROOM}

Creatine kinase (CK) is an enzyme that was described in 1965 as a biomarker for myocardial injury, having a sensitivity of $90 \%$, but a low specificity for the detection of myocardial infarction. ${ }^{17} \mathrm{CK}$ is detected in the serum at 12 hours from the onset of myocardial damage, peaks in 24 to 35 hours and normalizes in 48 to 72 hours, this dynamic making it inappropriate for early diagnosis of AMI. Despite its low specificity (increasing as well in other conditions such as hemolysis, muscle damage, rhabdomyolysis, burns, trauma, sepsis, or pregnancy), the creatine kinase assay is still used for the diagnosis of AMI due to its relatively low costs and wide availability. ${ }^{18,19}$

CK-MB (creatine kinase - myocardium brain) is one of the three major isoenzymes of $\mathrm{CK}$, found in high concentrations in the cardiac muscle, as well as in lower levels in the brain and skeletal muscles. ${ }^{20} \mathrm{CK}-\mathrm{MB}$ presents similar releasing patterns to that of $\mathrm{CK}$, and shows high specificity and sensitivity in detecting AMI, being more reliable in the 12-24-hour time window from the onset of AMI. Nevertheless, CK-MB has been shown effective in identifying AMI patients presenting in the emergency department with acute chest pain with a nonspecific ECG, thus allowing timely reperfusion therapies..$^{21,22}$

The current gold standard biomarker for myocardial infarction is considered to be cardiac troponin, which is highly specific for the cardiac muscle. ${ }^{23}$ Troponin assays have become widely available and are used in cardiovascular emergency settings, as they allow the identification of acute myocardial infarction at 6 hours from the onset of symptoms, having a sensitivity of $80.75 \%$ and a specificity of $63.8 \% .24,25$ The newer high-sensitivity assays can detect lower levels of troponin $(3 \mathrm{pg} / \mathrm{mL})$ within a shorter time from MI onset ( 3 to 4 hours from the onset of symptoms). ${ }^{24}$ Despite its high diagnostic accuracy, false positive results may be encountered, caused by troponin elevation in conditions with increased oxygen demand, reduced cardiac output, or ventricular strain, such as heart failure, pulmonary embolism, or septic shock. ${ }^{26}$ Other noncardiac causes for elevated troponin levels are anemia, renal failure, pulmonary disorders, ischemic and hemorrhagic cerebrovascular events, or intense exercise. ${ }^{27,28}$ Also, an increased level of troponin in heart failure patients has been linked to poorer outcomes, regardless of the presence of AMI, and elevated high-sensitive troponin expresses a considerably higher amount of myocardial injury in patients with heart failure, thus being a useful risk stratification biomarker. ${ }^{29-31}$ Moreover, a sub-study of the Global Registry of Acute Coronary Events (GRACE) on 16,318 non-ST elevation myocardial infarction patients revealed that increased levels of troponin were associated with higher rates of cardiac arrest, new heart failure, cardiogenic shock, and death. ${ }^{32}$

Myoglobin is a myocardial necrosis marker that can be detected in the blood stream within the first 3 hours from the onset of MI symptoms, but it lacks myocardial specificity, as it is raised in skeletal muscle damage, trauma, electrical cardioversion, renal disease, and patients with genetic muscular disorders. ${ }^{19}$ The kinetics of plasmatic myoglobin levels have been shown to be a reliable way for assessing the coronary artery patency following thrombolytic therapy in MI patients; increased baseline levels of this enzyme were observed in patients who did not respond to streptokinase, while there was a significantly higher myoglobin release among responders to thrombolysis as compared to non-responders. ${ }^{33}$ 
The Heart-Type Fatty Acid Binding Protein (H-FABP) is one of the most abundant proteins in the cardiac muscle, absent from the plasma or interstitial fluid, that is released during an episode of myocardial necrosis. ${ }^{34} \mathrm{H}$-FABP is released into the blood stream within 2 hours from symptom onset, with a peak at 4 to 6 hours, having an over $80 \%$ sensitivity in diagnosing AMI. Serial determinations of H-FABP are useful for the diagnosis of AMI, for identifying patients in need of reperfusion therapies, for detecting re-infarctions, as well as for estimating the infarct size. ${ }^{35}$ As in case of myoglobin, the levels of H-FABP can be elevated in other non-cardiac conditions such as renal failure, muscular trauma, traumatic cardiopulmonary resuscitation, or intramuscular injections, causing interference with the results of the assays. Some studies have questioned the role of myoglobin and H-FABP in the early detection of AMI, stating that cardiac troponins are more specific and possess higher diagnostic accuracy. ${ }^{36,37}$

\section{BIOMARKERS FOR RISK ASSESSMENT IN THE CORONARY CARE UNIT}

No reliable indicators have been established for the early risk assessment of developing heart failure or CS in AMI patients; however, various biomarkers that reflect the evolution towards ventricular dysfunction have been shown to associate with poorer outcomes after an acute coronary event.

Soluble ST 2 (sST2) is a novel marker expressing inflammation and interstitial fibrosis associated with heart failure that is up-regulated during myocardial strain as well as post-AMI. Soluble ST 2 has been shown to illustrate progressive decongestion in acute heart failure, and it has been demonstrated that circulating levels of SST2 decreased after 1 month in cases where mechanical circulatory assisting devices were used. ${ }^{38-40}$

Natriuretic peptides (NP) with the 3 isoenzymes: atrial NP, brain NP (BNP), and NT-proBNP, act as protective hormones that counteract the physiologic abnormalities of myocardial dysfunction and injury. ${ }^{41} \mathrm{BNP}$ has also diagnostic and prognostic value in myocardial infarction, as a serum level higher than $30 \mathrm{pmol} / \mathrm{L}$ was shown to be highly sensitive for diagnosing AMI, with a negative predictive value of $96 \% .{ }^{42}$ Furthermore, BNP is an efficient risk stratification tool for short- and long-term major adverse cardiac events following an AMI. In combination with echocardiographic assessment of left ventricular ejection fraction, BNP leads to an increased predictive capacity for death, heart failure, and repeated ischemic episodes. ${ }^{42,43}$
Co-peptin is a plasmatic peptide that increases in critical conditions such as shock, sepsis, stroke, or cardiovascular diseases, carrying diagnostic and prognostic value for myocardial injury. Persistently elevated levels of co-peptin after 3 to 5 days post-AMI are associated with higher rates of mortality and re-admissions for heart failure, and if associated with NT-proBNP assessment, it provides a more accurate risk prediction tool in AMI patients. 44,45

\section{INFLAMMATORY BIOMARKERS IN ACUTE CORONARY SYNDROMES AND CRITICAL CONDITIONS}

The systemic inflammatory response occurring in cardiogenic shock due to AMI is caused by myocardial necrosis, generalized tissue hypoperfusion, and hypoxia..$^{46}$ Several inflammatory cytokines, including interleukins (IL-6, IL8), tumor necrosis factor alpha (TNF- $\alpha$ ), Creactive protein (CRP), and soluble adhesion molecules, show increased levels in AMI complicated with CS. ${ }^{47-49}$ The elevated baseline levels of inflammatory biomarkers have high predictive power for the development of CS and mortality in this patient population. A sub-study of the COMMA trial showed that increased values in the serum levels of IL-6, TNF- $\alpha$, and CRP predicted the combined mortality and CS in AMI patients..$^{50}$

$\mathrm{C}$-reactive protein is an acute inflammatory response protein that can be elevated in subjects with atherosclerosis. This biomarker expresses an enhanced inflammation, and is especially increased in acute coronary syndromes. Furthermore, an increased level of CRP has been linked to worse outcomes following an acute coronary event. ${ }^{51-56}$ Elevated plasmatic CRP concentrations are associated with the worsening of the hemodynamic and neurohormonal state of heart failure patients, being a valuable predictor for ischemic and non-ischemic complications..$^{57}$ Also, elevated levels of high-sensitive CRP (hs-CRP) have been associated with increased short-term death rates in AMI patients who underwent primary coronary angioplasty. ${ }^{58-60}$

Interleukin-6 is the main promoter of CRP production at the level of the liver, being involved in acute inflammation, macrophage activity, hemato- and thrombopoiesis, and stem cell function. Also, the plasma concentration of IL-6 was shown to independently predict 30-day mortality in AMI patients with CS. ${ }^{49} \mathrm{~A}$ study on 75 AMI patients who underwent primary angioplasty found significant correlations between increased levels of IL- 6 and CRP and impairment of left ventricular systolic and diastolic function, as well as a good predictive power of these biomarkers for the development of systolic and diastolic dysfunction at 6 months. ${ }^{61}$ 
Pentatraxin-3 (PTX-3) is a novel biomarker linked with the inflammatory response in heart failure patients, being shown to correlate with poor evolution of heart failure and with major adverse cardiac events in patients with known diastolic heart failure. ${ }^{62,63}$ Also, PTX-3 levels have been proposed as prognostic markers for adverse events in patients with unstable angina and myocardial infarction. ${ }^{64}$

Procalcitonin is an inflammatory response biomarker produced by the parathyroid gland, which has been correlated with the severity of organ injury in AMI and CS, being used as a guiding tool for treatment and risk stratification in severe heart failure patients. ${ }^{65-68}$

\section{EMERGING BIOMARKERS IN MYOCARDIAL INFARCTION - EXTRACELLULAR MATRIX REMODELING AND MIRNAS}

The extracellular matrix (ECM) is the complex network within the intercellular space that has critical signaling functions. ECM provides the mechanical support for the myocardial fibers to perform their mechanical and biochemical function, and regulates cell proliferation, adhesion, and migration. ${ }^{69}$ Following myocardial infarction, cardiac cells undergo necrosis and are replaced by a scar that is mainly composed by ECM components. Several components of the ECM have been linked to cardiac fibrosis and remodeling after an acute cardiac event. Galectin-3 is a complex biomarker that is elevated in patients with important ventricular remodeling following AMI complicated with acute heart failure. The PRIDE trial demonstrated that elevated levels of Galectin-3 are highly predictive for 60-day mortality rates and re-admissions in the hospital for acute heart failure. ${ }^{70-74}$

Matrix metalloproteinases (MMPs), with their various isoenzymes, are biomarkers involved in the degradation of ECM components, together with serine proteases. ${ }^{75}$ MMP-2 is activated during cardiac injury due to increased oxidative stress, resulting in the cleavage of intracellular contractility substrates in the cardiac myocytes such as troponin I and myosin light chain. ${ }^{76}$ Concentrations of MMP-1 were shown to be significantly higher in patients with reduced systolic function. At the same time, MMP-2, MMP-9, and MMP-7, which express an enhanced collagen turnover, were more increased in subjects with diastolic dysfunction. ${ }^{77}$ According to the I-PRESERVE trial results, elevated levels of MMPs were associated with a higher incidence of the composite end-point of death due to heart failure, repeated hospitalizations, and all-cause mortality in patients with diastolic heart failure. ${ }^{78}$

Non-coding micro-ribonucleic acids (miRNAs) have recently emerged as useful risk stratification tools for the development of heart failure following an AMI. The identification of this new class of biomarkers could contribute to triggering prompt therapeutic intervention for preventing this potentially fatal complication. ${ }^{79}$ Many gene alterations have been examined for myocardial infarction response and the integration of mRNA and messenger RNAs in a genetic profile, which could help in elucidating the mechanisms of MI development, providing novel biomarkers for risk stratification following an acute coronary event. ${ }^{80-82}$ However, these promising tools are yet to be applied in clinical practice and require further research.

\section{HEMODYNAMIC MONITORING IN THE CORONARY CARE UNIT}

Various devices can be used in the CCUs, in order to provide essential information regarding the clinical and hemodynamic status of complicated AMI cases.

\section{NONINVASIVE MONITORING IN THE CCU}

One the most useful devices in the CCUs are represented by continuous surface electrocardiogram (ECG) monitoring systems, which offer continuous monitoring for 2-3 days following an AMI, or throughout the entire period of hemodynamic instability. These systems allow the early identification of arrhythmias and conduction disturbances as well as ST-segment and T-wave changes. ${ }^{83}$ ST-segment and T-wave changes can reveal repeated episodes of ischemia in the early post-AMI period, or can indicate an inefficient reperfusion therapy, which can serve as predictors for negative outcomes. ${ }^{84-88}$ Furthermore, it has been demonstrated that more than three ischemic events, or more than one hour repeated ischemic event on the continuous ECG tracing records indicate a three-vessel coronary artery disease or severe coronary atherosclerosis. $84,87,88$

The evaluation of arterial oxygen saturation with the use of pulse oximetry is used for noninvasively detecting the ventilatory status of the patients in the CCU. The technique is based on the photometric analysis of the pulse wave in the fingernail, requiring a systolic blood pressure of more than $85 \mathrm{mmHg}$. Therefore, clinical situations in which the patients present hypovolemia, low blood pressure, CS, or other types of shock associated with decreased tissular perfusion, can impair the evaluation of ventilatory status using this method. ${ }^{89}$ Tissular hypoperfusion is the most common event that proceeds multiple organ dysfunction during shock. ${ }^{90}$ Another method for the noninvasive assessment of tissue oxygenation includes near- 
infrared spectroscopy (NIRS), a technique that monitors muscular tissue oxygenation $\left(\mathrm{StO}_{2}\right)$ using infrared light absorption, through placement of a noninvasive sensor at the level of the thenar eminence. It has been shown that the normalization of $\mathrm{StO}_{2}$ levels is associated with improved outcomes in patients with hemorrhagic shock, and that low levels of the same parameter were correlated with the development of multiple organ dysfunction of trauma patients. ${ }^{90-93}$

The evaluation of body temperature can offer important information on the overall status of the critically ill patient, as fever is a negative prognostic factor that can indicate elevated systemic inflammation or infection, while a decreased peripheral temperature is a sign of decreased tissue perfusion..$^{94-98}$ Body temperature is assessed through peripheral (tympanic membrane, temporal artery, axillary, or oral), or central (pulmonary artery catheter, urinary bladder, esophageal, or rectal) methods. However, a meta-analysis on 75 studies that assessed the accuracy of peripheral thermometry for the estimation of core body temperature stated that peripheral thermometers should not be used if the body temperature will influence the therapeutic management, as they do not present an acceptable clinical accuracy. ${ }^{99,100}$ Fever can be an appropriate response to infection, and one study showed a lower in-hospital mortality rate in patients with peak temperatures of $39-39.4{ }^{\circ} \mathrm{C}$ compared to peak temperatures of $36.5-36.9^{\circ} \mathrm{C}(\mathrm{OR}, 0.56 ; 95 \% \mathrm{CI} 0.48-0.66) .{ }^{101}$

Diuresis monitoring (urine output on a given time frame) is of essence in the CCU, as it can provide relevant information on the renal function and hydration status of the patient, helping to guide fluid and diuretic therapy. ${ }^{94}$ A normal urine output ranges between $0.5-1 \mathrm{~mL} / \mathrm{kg} / \mathrm{h}$, while the presence of oliguria, a diuresis of less than 500 $\mathrm{mL}$ over a 24 -hour period, might indicate a decreased renal perfusion that could be related to the onset of acute heart failure. ${ }^{102,103}$ The presence of oliguria in critically ill subjects with AMI is a sensitive marker of acute kidney injury, and it has been shown to be linked to higher mortality rates in these patients. ${ }^{104,105}$ Patients with CS secondary to AMI present decreased arterial pressure and an overall organ hypoperfusion, which leads to hypotensioninduced renal injury. The main cause of acute kidney insufficiency in critically ill AMI patients is acute circulatory failure, through a pre-renal mechanism. ${ }^{106}$ A mean arterial pressure (MAP) of over $65 \mathrm{mmHg}$ is required to avoid organ failures, including renal dysfunction. ${ }^{107}$ An additional cause of renal dysfunction in patients with AMI is contrast-induced nephropathy, a complication of contrast media administration during coronary angiography and the third most common cause of hospital-acquired acute renal injury. ${ }^{108}$

\section{MONITORING HEMODYNAMIC STATUS IN THE CCU}

Usually, continuous recording of blood pressure and cardiac output (CO) is essential for the optimization of diuretic, inotropic, and vasodilator therapies in critical patients admitted in the CCU. ${ }^{109}$ The finger-cuff technology can provide continuous noninvasive monitoring of $\mathrm{BP}$ and cardiac output, using a cuff placed around the finger for continuous BP measurement and beat-to-beat cardiac output calculation through pulse contouring. ${ }^{110}$ Several studies have shown that this method is comparable to invasive monitoring systems. ${ }^{111,112}$

The noninvasive evaluation of stroke volume and cardiac output can be achieved using thoracic electrical impedance, ultrasound, and pulse contour analysis. ${ }^{113,114}$ The parameters assessed with cardio-impedance methods are the fluid content of the thoracic cavity, which has a negative correlation with thoracic impedance, ventricular preload, and left ventricular contractility, thus allowing the estimation of cardiac output, systemic vascular resistance, and the overall mechanical function of the left ventricle. However, systems that use electrical impedance to estimate $\mathrm{CO}$ cannot be used in certain situations that include septic shock, aortic valve replacement, uncontrolled hypertension, arrhythmias, the presence of an intra-aortic balloon pump, body weight of more than $155 \mathrm{~kg}$ or less than $30 \mathrm{~kg}$, as well as a heart rate above 200 beats per minute. ${ }^{115-117}$ Pulse contour analysis systems are based on the fact that the area under the systolic segment of the arterial pulse wave is correlated with the stroke volume. ${ }^{118}$ The first and most used device that uses pulse wave contour and thermo-dilution for $\mathrm{CO}$ evaluation is the minimally invasive PiCCO system (PULSION medical system, Munich, Germany), which requires a central venous line for cold saline injection and an arterial cannulation for placement of the temperature sensor that records the thermodilution curve. ${ }^{119}$ In addition, the PiCCO system can assess intrathoracic blood volume, global enddiastolic volume, and extravascular lung water, allowing the measurement of cardiac preload and pulmonary edema quantification. ${ }^{120}$ The Non-Invasive Cardiac Output (NICO) monitoring device is based on partial re-inhalation of $\mathrm{CO}_{2}$, using Fick's equation applied to carbon dioxide, and its accuracy is comparable to that of the gold standard thermodilution technique. ${ }^{121}$

Although transthoracic echocardiography cannot provide continuous hemodynamic measurements, it is the 
best bedside method to repeatedly evaluate the cardiac function, regional wall motion abnormalities, left ventricular ejection fraction, pulmonary artery pressure, aortic flows, and stroke volume, as well as acute complications occurring during the acute ischemic events, such as valve regurgitation, cardiac tamponade, left ventricular wall or papillary muscle rupture. ${ }^{122-124}$ Transesophageal echocardiography is a useful tool in hemodynamically unstable patients under mechanical ventilation; despite of the associated inter and intraprocedural variability, the method has been validated in agreement to the thermodilution method in measuring the cardiac output. ${ }^{125,126}$ Moreover, the esophageal Doppler flexible probe can measure the aortic flow by multiplying the cross-sectional area with the velocity, which will allow the estimation of the left ventricular stroke volume. The major limitation of this method is that it provides measurements from the descending aorta (only $70 \%$ of the total flow), and that discrepancies appear in case of aortic coarctation, aneurysms, or in the presence of an intra-aortic balloon pump. ${ }^{127} \mathrm{Nev}$ ertheless, the evaluation of stroke volume with esophageal Doppler has been shown to be in concordance with well-established invasive methods. ${ }^{128,129}$

\section{INVASIVE MONITORING OF HEMODYNAMIC PARAMETERS IN THE CORONARY CARE UNIT}

Invasive monitoring in the CCU is performed when the hemodynamic status of the patients is not stabilized and requires additional invasive measures. ${ }^{130}$

The invasive evaluation of blood pressure is achieved by placing a catheter in a superficial artery (radial, femoral, or pedis artery), which is connected to a transducer that transforms the mechanical pulse wave into a pressure curve. Analysis of the invasive arterial pressure waveform allows the estimation of $\mathrm{CO}$ and ventricular ejection fraction, and the invasive measurements are performed simultaneously with the noninvasive evaluation of blood pressure. ${ }^{131,132}$

Central venous pressure (CVP) is a marker that illustrates intravascular volume and right ventricular function, being measured by inserting a catheter in the superior caval system (subclavian or internal jugular vein), with continuous ECG recording, under local anesthesia. An increased CVP is suggestive of decreased ventricular function, increased venous return, increased systemic vascular resistance or elevated intrathoracic pressures. The assessment of CVP is of utmost importance in hemodynamically unstable AMI patients, as it guides fluid administration in this critical condition. ${ }^{133}$
The invasive assessment of $\mathrm{CO}$ and stroke volume is performed by Swan Ganz catheterization using the thermodilution method, which also allows the evaluation of right cardiac pressures and the pulmonary capillary wedge pressure, being largely used in CCUs for invasive hemodynamic monitoring. ${ }^{134-137}$ Other invasively assessed parameters used in the CCU for critical AMI patients are those reflecting ventricular contractility such as the left ventricular stroke volume and the mechanical work, which can indicate whether inotropes or vasodilator therapies are required. ${ }^{138,139}$

The pressures in the right ventricular and pulmonary artery illustrate the pulmonary circulation, while the capillary wedge pressure reflects the end-diastolic pressure in the left ventricle, indicating the preload alteration and estimating the systolic and diastolic function of the left heart chambers. ${ }^{140,141}$ Furthermore, the pulmonary capillary wedge pressure evaluation provides information on the hemodynamic impact of various acute complication of MI such as ischemic mitral regurgitation, interventricular septum defect, or newly developed intracardiac shunts of papillary muscle rupture with acute mitral regurgitation. ${ }^{1 / 42}$

\section{CONCLUSION}

CS is a life-threatening complication of AMI that requires intensive monitoring of the hemodynamic, biochemical, and inflammatory status, being essential in providing a proper and complex diagnostic and therapeutic management, as well as for accurate risk stratification. Complex serum biomarker panels able to identify early changes in the clinical status, to detect high risk patients, and to evaluate response to treatment should be introduced in current clinical practice for a proper and prompt therapeutic intervention. Also, various invasive and noninvasive monitoring techniques should be used as complementary tools for guiding diagnosis and treatment in acute coronary care units.

\section{CONFLICT OF INTEREST}

Nothing to declare.

\section{REFERENCES}

1. Reynolds HR, Hochman JS. Cardiogenic shock: current concepts and improving outcomes. Circulation. 2008;117:686697. doi:10.1161/CIRCULATIONAHA.106.613596.

2. Hochman JS. Cardiogenic shock complicating acute myocardial infarction: expanding the paradigm. Circulation. 2003;107:2998-3002. doi: 10.1161/01.CIR.0000075927.67673. F2. 
3. Khalid L, Dhakam S. A Review of Cardiogenic Shock in Acute Myocardial Infarction. Current Cardiology Reviews. 2008;4:34-40. doi: 10.2174/157340308783565456.

4. Hochman JS, Sleeper LA, Webb JG, et al. Early revascularization in acute myocardial infarction complicated by cardiogenic shock. SHOCK Investigators. Should we emergently revascularize occluded coronaries for cardiogenic shock. N Engl J Med. 1999;341:625-34. doi: 10.1056/ NEJM199908263410901.

5. Fox KA, Steg PG, Eagle KA, et al. Decline in rates of death and heart failure in acute coronary syndromes, 1999-2006. JAMA. 2007; 297:1892-1900. doi:10.1001/jama.297.17.1892.

6. Goldberg RJ, Spencer FA, Gore JM, LessardD, Yarzebski J.Thirty Year Trends (1975-2005) in the Magnitude, Management, and Hospital Death Rates Associated With Cardiogenic Shock in Patients with Acute Myocardial Infarction: A Population-Based Perspective. Circulation. 2009;119:12111219. doi:10.1161/CIRCULATIONAHA.108.814947.

7. Babaev A, Frederick PD, Pasta DJ, et al. Trends in management and outcomes of patients with acute myocardial infarction complicated by cardiogenic shock. JAMA. 2005; 294:448-454. doi: 10.1001/jama.294.4.448.

8. TRIUMPH Investigators, Alexander $\mathrm{JH}$, Reynolds $\mathrm{HR}$, et al. Effect of tilarginine acetate in patients with acute myocardial infarction and cardiogenic shock: the TRIUMPH randomized controlled trial. JAMA. 2007;297:1657-1666. doi: 10.1001/ jama.297.15.joc70035.

9. Werdan $K, \operatorname{Ru} \beta M$, Buerke $M$, et al. Cardiogenic shock due to myocardial infarction: diagnosis, monitoring and treatment: a German-Austrian S3 Guideline. Dtsch Arztebl Int. 2012;109:343-51. doi: 10.3238/arztebl.2012.0343.

10. Reynolds HR, Hochman JS. Cardiogenic shock: current concepts and improving outcomes. Circulation. 2008;117:686697. doi: 10.1161/CIRCULATIONAHA.106.613596.

11. Bartling B, Milting $\mathrm{H}$, Schumann $\mathrm{H}$, et al. Myocardial gene expression of regulators of myocyte apoptosis and myocyte calcium homeostasis during hemodynamic unloading by ventricular assist devices in patients with end-stage heart failure. Circulation. 1999;100:216-223. https://doi. org/10.1161/01.CIR.100.suppl_2.II-216.

12. Li YY, Feng Y, McTiernan CF, et al. Downregulation of matrix metalloproteinases and reduction in collagen damage in the failing human heart after support with left ventricular assist devices. Circulation. 2001;104:1147-1152.

13. Delgado R 3rd, Radovancevic B, Massin EK, Frazier OH, Benedict C. Neurohormonal changes after implantation of a left ventricular assist system. ASAIO J. 1998;44:299-302.

14. Shah NR, Bieniarz MC, Basra SS, et al. Serum biomarkers in severe refractory cardiogenic shock. JACC Heart Fail. 2013;1:200-6. doi: 10.1016/j.jchf.2013.03.002.

15. Chiotoroiu A, Buicu F, Benedek T. Recent advances in biomarker discovery - from serum to imaging-based biomarkers for a complex assessment of heart failure patients. Journal of Interdisciplinary Medicine. 2016;1:125130. doi: 10.1515/jim-2016-0045.

16. Meredith AJ, Dai DLY, Chen V, et al. Circulating biomarker responses to medical management vs. mechanical circulatory support in severe inotrope-dependent acute heart failure. Esc Heart Failure. 2016;3:86-96.doi:10.1002/ehf2.12076.

17. Duma RJ, Siegel AL. Serum creatinine phosphokinase in acute myocardial infarction: diagnostic value. Arch Intern Med. 1965;115:443-51.
18. Pierce GF, Jaffe AS. Increased creatine kinase MB in the absence of acute myocardial infarction. Clin Chem. 1986;32:2044-51.

19. Al-Hadi HA, Fox KA. Cardiac Markers in the Early Diagnosis and Management of Patients with Acute Coronary Syndrome. Sultan Qaboos University Medical Journal. 2009;9:231-246.

20. Saenger AK, Jaffe AS. The use of biomarkers for the evaluation and treatment of patients with acute coronary syndromes. Med Clin North Am. 2007;91:657-681. doi: 10.1016/j. mcna.2007.04.001.

21. Irvin RG, Cobb FR, Roe CR. Acute myocardial infarction and MB creatine phosphokinase. Relationship between onset of symptoms of infarction and appearance and disappearance of enzyme. Arch Intern Med. 1980;140:329-334. doi:10.1001/ archinte.1980.00330150043014.

22. Gibler WB, Young GP, Hedges JR et al. Acute myocardial infarction in chest pain patients with non-diagnostic ECGs: serial CK-MB sampling in the emergency department. The Emergency Medicine Cardiac Research Group. Ann Emerg Med. 1992;21:504-512.

23. Daubert MA, Jeremias A. The utility of troponin measurement to detect myocardial infarction: review of the current findings. Vasc Health Risk Manag. 2010;6:691-699.

24. del Val Martin D, Sanmartin Fernandez MS, Zamorano Gomez JL. Biomarkers in acute coronary syndrome. IJC Metabolic \& Endocrine. 2015;8:20-23. https://doi.org/10.1016/j. ijcme.2015.04.003

25. Tucker JF, Collins RA, Anderson AJ, Hauser J, Kalas J, Apple FS. Early diagnostic efficiency of cardiac troponin I and Troponin $\mathrm{T}$ for acute myocardial infarction. Acad Emerg Med. 1997;4:13-21.

26. Vaughan L. Biomarkers in acute medicine. Medicine. 2013;41:136-141. doi: http://dx.doi.org/10.1016/j. mpmed.2013.01.001.

27. Tanindi A, Cemri M. Troponin elevation in conditions other than acute coronary syndromes. Vasc Health Risk Manag. 2011;7:597-603. doi:10.2147/VHRM.S24509.

28. Gunnewiek JM, Van Der Hoeven JG. Cardiac troponin elevations among critically ill patients. Curr Opin Crit Care. 2004;10:342-346.

29. Peacock WF 4th, De Marco T, Fonarow GC, et al. Cardiac Troponin and Outcome in Acute Heart Failure. N Engl J Med. 2008;358:2117-2126. doi: 10.1056/NEJMoa0706824.

30. Sato Y, Yamada T, Taniguchi T, et al. Persistently increased serum concentrations of cardiac troponin $\mathrm{T}$ in patients with idiopathic dilated cardiomyopathy are predictive of adverse outcomes. Circulation. 2001;103:369-74.

31. Pascual-Figal DA, Manzano-Fernandez S, Boronat M, et al. Soluble ST2, high-sensitivity troponin T- and N-terminal pro-B-type natriuretic peptide: complementary role for risk stratification in acutely decompensated heart failure. Eur J Heart Fail. 2011;13:718-725. doi: 10.1093/eurjhf/hfro47.

32. Jolly SS, Shenkman H, Brieger D, et al. Quantitative troponin and death, cardiogenic shock, cardiac arrest and new heart failure in patients with non-ST-segment elevation acute coronary syndromes (NSTE ACS): insights from the Global Registry of Acute Coronary Events. Heart. 2011;97:197-202. doi: 10.1136/hrt.2010.195511.

33. Iqbal MP, Kazmi KA, Mehboobali N, Rahbar A. Myoglobin - a marker of reperfusion and a prognostic indicator in patients with acute myocardial infarction. Clin Cardiol. 2004;27:14450. 
34. Alhadi HA, Fox KA. Do we need additional markers of myocyte necrosis: the potential value of heart fatty-acid-binding protein. QJM. 2004;97:187-198.

35. Colli A, Josa M, Pomar JL, Mestres CA, Gherli T. Heart fatty acid binding protein in the diagnosis of myocardial infarction: where do we stand today? Cardiology. 2007;108:4-10. doi: 10.1159/000095594.

36. Alansari SE, Croal BL. Diagnostic value of heart fatty acid binding protein and myoglobin in patients admitted with chest pain. Ann Clin Biochem. 2004;41:391-396. doi: 10.1258/0004563041731565.

37. Ilva T, Lund J, Porela P, et al. Early markers of myocardial injury: cTnI is enough. Clin Chim Acta. 2009;400:82-85. doi: 10.1016/j.cca.2008.10.005.

38. Manzano-Fernandez S, Januzzi JL, Pastor-Perez FJ, et al. Serial monitoring of soluble interleukin family member ST2 in patients with acutely decompensated heart failure. Cardiology. 2012;122:158-166. doi: 10.1159/000338800.

39. Caselli C, D'Amico A, Ragusa R, et al. IL-33/ST2 pathway and classical cytokines in end-stage heart failure patients submitted to left ventricular assist device support: a paradoxic role for inflammatory mediators? Mediators Inflamm. 2013;2013:498703. doi: 10.1155/2013/498703.

40. Meredith AJ, Dai DLY, Chen V, et al. Circulating biomarker responses to medical management vs. mechanical circulatory support in severe inotrope-dependent acute heart failure. Esc Heart Failure. 2016;3:86-96. doi:10.1002/ehf2.12076.

41. Yasue $H$, Yoshimura $M$, Sumida $H$, et al. Localization and mechanism of secretion of B-type natriuretic peptide in comparison with those of A-type natriuretic peptide in normal subjects and patients with heart failure. Circulation. 1994; 90:195-203.

42. Richards AM, Nicholls MG, Espiner EA, et al. B-type natriuretic peptides and ejection fraction for prognosis after myocardial infarction. Circulation. 2003;107:2786-2792. doi: 10.1161/01.CIR.0000070953.76250.B9.

43. de Lemos JA, Morrow DA, Bentley JH, et al. The prognostic value of B-type natriuretic peptide in patients with acute coronary syndromes. N Engl J Med. 2001;345:1014-1021. doi: 10.1056/NEJMoa011053.

44. Khan SQ Dhillon OS, O'Brien RJ, et al. C-terminal provasopressin (copeptin) as a novel and prognostic marker in acute myocardial infarction: Leicester Acute Myocardial Infarction Peptide (LAMP) study. Circulation. 2007;115:21032110. doi: 10.1161/CIRCULATIONAHA.106.685503.

45. Reichlin T, HochholzerW, Stelzig C, et al. Incremental value of copeptin for rapid rule out of acute myocardial infarction. J Am Coll Cardiol. 2009;54:60-68. doi:10.1016/j. jacc.2009.01.076.

46. Shpektor A. Cardiogenic shock: the role of inflammation. Acute CardCare.2010;12:115-118.doi:10.3109/17482941.2010.523705.

47. Kohsaka S, Menon V, Lowe AM, et al. Systemic inflammatory response syndrome after acute myocardial infarction complicated by cardiogenic shock. Arch Intern Med. 2005;165:1643-1650. doi: 10.1001/archinte.165.14.1643.

48. Pudil R, Krejsek J, Pidrman V, Gregor J, Tichy M, Bures $\mathrm{J}$. Inflammatory response to acute myocardial infarction complicated by cardiogenic shock. Acta Medica. 2001;44:149151.

49. Geppert A, Dorninger A, Delle-Karth G, Zorn G, Heinz G, Huber K. Plasma concentrations of interlukin-6, organ failure, vasopressor support, and successful revascularization in predicting 30-day mortality of patients with cardiogenic shock complicating acute myocardial infarction. Crit Care Med. 2006;34:2035-2042. doi: 10.1097/01.CCM.0000228919.33620. D9.

50. Theroux P, Armstrong PW, Mahaffey KW et al. Prognostic significance of blood markers of infl ammation in patients with ST-elevation myocardial infarction undergoing primary angioplasty and effects of pexelizumab, a C5 inhibitor: A substudy of the COMMA trial. Eur Heart J. 2005:26;19641970. doi:10.1093/eurheartj/ehi292.

51. Mueller C, Buettner HJ, Hodgson JM, et al. Inflammation and long-term mortality axter non-ST elevation acute coronary syndrome treated with a very early invasive strategy in 1042 consecutive patients. Circulation. 2002;105:1412-1415.

52. Schiele F, Meneveau N, Seronde MF, et al. C-reactive proteinimproves risk prediction in patients with acute coronary syndromes. Eur Heart J. 2010;31:290-297. doi:10.1093/eurheartj/ehp273.

53. Meijers WC, van der Velde AR, de Boer RA. The ARCHITECT galectin-3 assay: comparison with other automated and manual assays for the measurement of circulating galectin-3 levels in heart failure. Expert Rev Mol Diagn. 2014;14:257266. doi: 10.1586/14737159.2014.892421.

54. Giannitsis E, Katus HA. Troponins and high-sensitivity troponins as markers of necrosis in $\mathrm{CAD}$ and heart failure. Herz. 2009;34:600-606. doi: 10.1007/s00059-009-3306-6.

55. Daniels LB, Bayes-Genis A. Using ST2 in cardiovascular patients: a review. Future Cardiol. 2014;10:525-539. doi: 10.2217/fca.14.36.

56. De Berardinis B, Gaggin HK, Magrini L, et al. Comparison between admission natriuretic peptides, NGAL and sST2 testing for the prediction of worsening renal function in patients with acutely decompensated heart failure. Clin Chem Lab Med. 2014;53:613-621. http://dx.doi.org/10.1515/cclm2014-0191.

57. Anand IS, Latini R, Florea VG, et al. C-Reactive Protein in Heart Failure Prognostic Value and the Effect of Valsartan. Circulation. 2005;112:1428-1434. doi: 10.1161/ CIRCULATIONAHA.104.508465.

58. Ribeiro DRP, Ramos AM, Vieira PL, et al. High-Sensitivity C-Reactive Protein as a Predictor of Cardiovascular Events after ST-Elevation Myocardial Infarction. Arquivos Brasileiros de Cardiologia. 2014;103:69-75. doi:10.5935/abc.20140086.

59. Yip HK, Hang CL, Fang CY, et al. Level of high-sensitivity C-reactive protein is predictive of 30-day outcomes in patients with acute myocardial infarction undergoing primary coronary intervention. Chest. 2005;127:803-808. doi: 10.1378/chest.127.3.803.

60. Magdalen R, Hertz I, Merlon H, Weiner P, Mohammedi I, Robert D. The relation between preprocedural C-reactive protein levels and early and late complications in patients with acute myocardial infarction undergoing interventional coronary angioplasty. Clin Cardiol. 2004;27:163-168.

61. Karpiński L, Płaksej R, Kosmala W, Witkowska M. Serum levels of interleukin-6, interleukin-10 and C-reactive protein in relation to left ventricular function in patients with myocardial infarction treated with primary angioplasty. Kardiol Pol. 2008;66:1279-1285.

62. Matsubara J, Sugiyama S, Nozaki T, et al. Incremental Prognostic Significance of the Elevated Levels of Pentraxin 3 
in Patients With Heart Failure With Normal Left Ventricular Ejection Fraction. J Am Heart Assoc. 2014;3:1-11. doi:10.1161/ JAHA.114.000928.

63. Guo R, Li Y, Wen J, Li W, Xu Y. Elevated plasma level of pentraxin-3 predicts in-hospital and 30-day clinical outcomes in patients with non-ST-segment elevation myocardial infarction who have undergone percutaneous coronary intervention. Cardiology. 2014;129:178-188. doi: 10.1159/000364996.

64. Latini R, Maggioni AP, Peri G, et al. Prognostic significance of the long pentraxin PTX3 in acute myocardial infarction. Circulation. 2004;110:2349-2354. doi: 10.1161/01. CIR.0000145167.30987.2E.

65. Mallick A, Lanuzzi JL. Biomarkers in acute heart failure. Rev Esp Cardiol. 2015;68:514-525. doi: 10.1016/j.rec.2015.02.009.

66. Bayes-Genis A, Ordonez-Llanos J. Multiple biomarker strategies for risk stratification in heart failure. Clin Chim Acta. 2015;443:120-125. doi: 10.1016/j.cca.2014.10.023.

67. De Antonio M, Lupon J, Galan A, Vila J, Urrutia A, BayesGenis A. Combined use of high-sensitivity cardiac troponin $\mathrm{T}$ and $\mathrm{N}$-terminal pro-B type natriuretic peptide improves measurements of performance over established mortality risk factors in chronic heart failure. Am Heart J. 2012;163:821828. doi: 10.1016/j.ahj.2012.03.004.

68. Maisel AS, Mueller C, Fitzgerald R, et al. Prognostic utility of plasma neutrophil gelatinase-associated lipocalin in patients with acute heart failure: the NGAL EvaLuation Along with B-type NaTriuretic Peptide in acutely decompensated heart failure (GALLANT) trial. Eur J Heart Fail. 2011;13:846-851. doi: 10.1093/eurjhf/hfro87.

69. Holmes JW, Borg TK, Covell JW. Structure and mechanics of healingmyocardialinfarcts.AnnuRevBiomedEng.2005;7:223253. doi:10.1146/annurev.bioeng.7.060804.100453.

70. van Kimmenade RR, Januzzi JL Jr, Ellinor PT, et al. Utility of amino-terminal pro-brain natriuretic peptide, galectin-3, and apelin for the evaluation of patients with acute heart failure. J Am Coll Cardiol. 2006;48:1217-1224. doi: 10.1016/j. jacc.2006.03.061.

71. Bayes-Genis A, Ordonez-Llanos J. Multiple biomarker strategies for risk stratification in heart failure. Clin Chim Acta. 2015;443:120-125. doi: 10.1016/j.cca.2014.10.023.

72. Ky B, French B, Levy WC, et al. Multiple biomarkers for risk prediction in chronic heart failure. Circ Heart Fail. 2012; 5:183190. doi: 10.1161/CIRCHEARTFAILURE.111.965020.

73. Daniels LB, Bayes-Genis A. Using ST2 in cardiovascular patients: a review. Future Cardiol. 2014;10:525-539. doi: 10.2217/fca.14.36.

74. de Boer RA, Lok DJ, Jaarsma T, et al. Predictive value of plasma galectin-3 levels in heart failure with reduced and preserved ejection fraction. Ann Med 2011;43:60-68. doi: 10.3109/07853890.2010.538080.

75. Singh RB, Dandekar SP, Elimban V, Gupta SK, Dhalla NS. Role of proteases in the pathophysiology of cardiac disease. Mol Cell Biochem. 2004;263:241-256.

76. Ali MA, Schulz R. Activation of MMP-2 as a key event in oxidative stress injury to the heart. Front Biosci (Landmark Ed). 2009;14:699-716.

77. Ahmed SH, Clark LL, Pennington WR, et al. Matrix metalloproteinases/tissue inhibitors of metalloproteinases: relationship between changes in proteolytic determinants of matrix, composition and structural, functional and clinical manifestations of hypertensive heart disease. Circulation 2006;113:2089-2096. doi: 10.1161/ CIRCULATIONAHA.105.573865.

78. Krum H, Elsik M, Schneider HG, et al. Relation of peripheral collagen markers to death and hospitalization in patients with heart failure and preserved ejection fraction: results of the I-PRESERVE collagen substudy. Circ Heart Fail. 2011:4:561568. doi:10.1161/CIRCHEARTFAILURE.110.960716.

79. Rao PK, Toyama Y, Chiang HR et al. Loss of cardiac microRNAmediated regulation leads to dilated cardiomyopathy and heart failure. Circ Res. 2009;105:585-594. doi:10.1161/ CIRCULATIONAHA.105.573865.

80. Wang Y, Pan X, Fan Y, et al. Dysregulated expression of microRNAs and mRNAs in myocardial infarction. Am J Transl Res. 2015;7:2291-2304.

81. Stanton LW, Garrard LJ, Damm D, et al. Altered patterns of gene expression in response to myocardial infarction. Circ Res. 2000;86:939-945.

82. Kiliszek $M$, Burzynska B, Michalak $M$, et al. Altered gene expression pattern in peripheral blood mononuclear cells in patients with acute myocardial infarction. PLoS One. 2012;7:e50054. doi: 10.1371/journal.pone.0050054.

83. Drew BJ, Califf RM, Funk M, et al. Practice Standards for Electrocardiographic Monitoring in Hospital Settings: An American Heart Association Scientific Statement From the Councils on Cardiovascular Nursing, Clinical Cardiology, and Cardiovascular Disease in the Young: Endorsed by the International Society of Computerized Electrocardiology and the American Association of Critical Care Nurses. Circulation. 2004;110:2721-2746. doi: 10.1161/01. CIR.0000145144.56673.59.

84. Stevenson RN, Marchant BG, Ranjadayalan K, Uthayakumar S, Timmis AD. Holter ST monitoring early after acute myocardial infarction: mechanisms of ischaemia in patients treated by thrombolysis. Br Heart J. 1993;70:433-437.

85. Johanson P, Jernberg T, Gunnarsson G, Lindahl B, Wallentin L, Dellborg M. Prognostic value of ST $\neg$ segment resolution $\neg$ when and what to measure. Eur Heart J. 2003;24:337-345 doi: https://doi.org/10.1016/S0195-668X(02)00739-X.

86. Flanders SA. ST $\neg$ Segment Monitoring: Putting Standards Into Practice. AACN Adv Crit Care. 2007;18:275-284.

87. Leung JM, Voskanian A, Bellows AM. Automated electrocardiograph ST segment trending monitors: accuracy in detecting myocardial ischemia. Anesth Analg. 1998;87:410.

88. Shanewise J. How to Reliably Detect Ischemia in the Intensive Care Unit and Operating Room. Semin Cardiothorac Vasc Anesth. 2006;10:101-109. doi: 10.1177/108925320601000117.

89. Opincariu D, Chitu M, Rat N, Benedek I. Integrated ST segment elevation scores and in-hospital mortality in STEMI patients undergoing primary PCI. Journal of Cardiovascular Emergencies. 2016;2:114-121. doi: 10.1515/jce-2016-0018.

90. Ikossi DG, Knudson MM, Morabito DJ, et al. Continuous muscle tissue oxygenation in critically injured patients: a prospective observational study. J Trauma. 2006;61:780-790. doi: 10.1097/01.ta.0000239500.71419.58.

91. Nicks BA, Campos KM, Bozeman WP. Association of low noninvasive near-infrared spectroscopic measurements during initial trauma resuscitation with future development of multiple organ dysfunction. World J Emerg Med. 2015;6:105110. doi: 10.5847/wjem.j.1920-8642.2015.02.004. 
92. Miner J, Nelson R, Hayden L. The effect of near infrared spectroscopy monitoring on the treatment of patients presenting to the emergency department in shock. Crit Care Med. 2010;38:S861.

93. Lima A, van Bommel J, Jansen TC, Ince C, Bakker J. Low tissue oxygen saturation at the end of early goal-directed therapy is associated with worse outcome in critically ill patients. Crit Care. 2009;13(Suppl5):S13. doi: 10.1186/cc8011.

94. Mariscalo G, Musumeci F. Fluid management in the cardiothoracic intensive care unit: diuresis - diuretics and hemofiltration. Curr Opin Anaesthesiol. 2014;27:133-139.doi: 10.1097/ACO.0000000000000055.

95. Jakovljevic DG, Moore S, Hallsworth K, Fattakhova G, Thoma C, Trenell MI. Comparison of cardiac output determined by bioimpedance and bioreactance methods at rest and during exercise. J Clin Monit Comput. 2012;26:63-68. doi: 10.1007/ s10877-012-9334-4.

96. Laupland KB, Shahpori R, Kirkpatrick AW, et al. Occurrence and outcome of fever in critically ill adults. Crit Care Med. 2008;36:1531. doi: 10.1097/CCM.ob013e318170efd3.

97. Ryan M, Levy MM. Clinical review: fever in intensive care unit patients. Crit Care. 2003;7:221-225.

98. Niven DJ, Le' ger C, Stelfox HT, Laupland KB. Fever in the critically ill: a review of epidemiology, immunology, and management. J Intensive Care Med. 2012;27:290-297. doi: 10.1177/0885066611402463.

99. Niven DJ, Gaudet JE, Laupland KB, Mrklas KJ, Roberts DJ, Stelfox HT. Accuracy of Peripheral Thermometers for Estimating Temperature: A Systematic Review and Metaanalysis. Ann Intern Med. 2015;163:768-777. doi: 10.7326/ M15-1150.

100. Jefferies S, Weatherall M, Young P, Beasley R. A systematic review of the accuracy of peripheral thermometry in estimating core temperatures among febrile critically ill patients. Crit Care Resusc. 2011;13:194-199.

101. Young PJ, Saxena M, Beasley R, et al. Early peak temperature and mortality in critically ill patients with or without infection. Intensive Care Med. 2012. doi: 10.1007/s00134-0122478-3.

102. Jeremy S. Bock and Stephen S. Gottlieb. Cardiorenal Syndrome. Circulation. 2010;121:2592-2600. https://doi.org/10.1161/ CIRCULATIONAHA.109.886473.

103. Md Ralib A, Pickering JW, Shaw GM, Endre ZH. The urine output definition of acute kidney injury is too liberal. Critical Care. 2013;17:R112. doi:10.1186/cc12784.

104. Prowle JR, Liu YL, Licari E, et al. Oliguria as predictive biomarker of acute kidney injury in critically ill patients. Crit Care. 2011;17:R172. doi: 10.1186/cc10318.

105. Macedo E, Malhotra R, Bouchard J, Wynn SK, Mehta RL. Oliguria is an early predictor of higher mortality in critically ill patients. Kidney Int. 2011;80:760-767. doi: 10.1038/ ki.2011.150.

106. Uchino S, Kellum JA, Bellomo R, et al. Beginning and Ending Supportive Therapy for the Kidney (BEST Kidney) Investigators. Acute renal failure in critically ill patients: a multinational, multicenter study. JAMA. 2005;294:813-818. doi: 10.1001/jama.294.7.813.

107. Antonelli M, Levy M, Andrews PJ, et al. Hemodynamic monitoring in shock and implications for management. International Consensus Conference, Paris, France, 2728 April 2006. Intensive Care Med. 2007;33:575-590. doi: 10.1007/s00134-007-0531-4.
108. McCullough PA, Adam A, Becker CR, et al. Epidemiology and prognostic implications of contrast-induced nephropathy. Am J Cardiol. 2006;98:5K-13K.

109. Mohammed NMA, Mahfouz A, Achkar K, Rafie IM, Hajar R. Contrast-induced Nephropathy. Heart Views. 2013;14:106116. doi:10.4103/1995-705X.125926.

110. Truijen J, van Lieshout JJ, Wesselink WA, Westerhof BE. Noninvasive continuous hemodynamic monitoring. J Clin Monit Comput. 2012;26:267-278. doi:10.1007/s10877-0129375-8.

111. Ameloot K, Palmers PJ, Malbrain ML. The accuracy of noninvasive cardiac output and pressure measurements with finger cuff: a concise review. Curr Opin Crit Care. 2015;21:232239. doi: 10.1097/MCC.0000000000000198.

112. Martina JR, Westerhof BE, van Goudoever J, et al. Noninvasive continuous arterial blood pressure monitoring with Nexfin ${ }^{\circledR}$. Anesthesiology. 2012;116:1092-1103. doi: 10.1097/ ALN.ob013e31824f94ed.

113. Kim SH, Lilot $\mathrm{M}$, Sidhu KS, et al. Accuracy and precision of continuous noninvasive arterial pressure monitoring compared with invasive arterial pressure: a systematic review and meta-analysis. Anesthesiology. 2014;120:1080-1097. doi: 10.1097/ALN.0000000000000226.

114. Keren H, Burkhoff D, Squara P. Evaluation of a noninvasive continuous cardiac output monitoring system based on thoracic bioreactance. Am J Physiol Heart Circ Physiol. 2007;293:H583-H589. doi: 10.1152/ajpheart.00195.2007.

115. van Lieshout JJ, Toska K, van Lieshout EJ, Eriksen M, Walløe $\mathrm{L}$, Wesseling KH. Beat-to-beat noninvasive stroke volume from arterial pressure and Doppler ultrasound. Eur J Appl Physiol. 2003;90:131-137.

116. Engore M, Barbee D. Comparison of Cardiac Output Determined by Bioimpedance, Thermodilution, and the Fick Method. Am J Crit Care. 2005;14:40-45.

117. Ball TR, Culp BC, Patel V, et al. Comparation of the endotracheal cardiac output monitor to thermodilution in cardiac surgery patients. J Cardiothorac Vasc. 2010;24:762766. doi: 10.1053/j.jvca.2010.04.008.

118. Babbs CF. Noninvasive measurement of cardiac stroke volume using pulse wave velocity and aortic dimensions: a simulation study. BioMedical Engineering OnLine. 2014;13:137. doi:10.1186/1475-925X-13-137.

119. Sakka SG, Kozieras J, Thuemer O, van Hout N. Measurement of cardiac output: a comparison between transpulmonary thermodilution and uncalibrated pulse contour analysis. Br J Anaesth. 2007;99:337-342.

120. Oren-Grinberg A. The PiCCO Monitor. Int Anesthesiol Clin. 2010;48:57-85. doi: 10.1097/AIA.ob013e3181c3dc11.

121. Young BP, Low LL. Noninvasive monitoring cardiac output using partial CO(2) rebreathing. Crit Care Clin. 2010;26:383392. doi: 10.1016/j.ccc.2009.12.002.

122. Cholley BP, Vieillard-Baron A, Mebazaa A. Echocardiography in the ICU: time for widespread use! Intensive Care Med. 2006;32:9-10. doi: 10.1007/s00134-005-2833-8.

123. Wilansky S. Echocardiography in the Assessment of Complications of Myocardial Infarction. Tex Heart Inst J. 1991;18:237-242.

124. Esmaeilzadeh M, Parsaee $M$, Maleki $M$. The Role of Echocardiography in Coronary Artery Disease and Acute Myocardial Infarction. J Tehran Heart Cent. 2013;8:1-13.

125. Bródka J, Tułecki Ł, Ciurysek M, Gburek T. Thermodilution vs transesophageal echocardiography for cardiac output 
measurement in patients with good left ventricle function. Anestezjol Intens Ter. 2010;42:15-18.

126. Perrino AC Jr, Harris SN, Luther MA. Intraoperative determination of cardiac output using multiplane transesophageal echocardiography: a comparison to thermodilution. Anesthesiology. 1998;89:350-357.

127. Mehta Y, Arora D. Newer methods of cardiac output monitoring. World J Cardiol. 2014;6:1022-1029. doi:10.4330/ wjc.v6.i9.1022

128. Laupland KB, Bands CJ. Utility of esophageal Doppler as a minimally invasive hemodynamic monitor: a review. Can J Anaesth. 2002;49:393-401. doi: 10.1007/BF03017329.

129. Sharma J, Bhise M, Singh A, Mehta Y, Trehan N. Hemodynamic measurements after cardiac surgery: transesophageal Doppler versus pulmonary artery catheter. J Cardiothorac Vasc Anesth. 2005;19:746-750.

130. Camporata L, Beale R. Pitfalls in haemodynamic monitoring based on the arterial pressure waveform. Crit Care. 2010;14:124. doi: 10.1186/cc8845.

131. Thom O, Taylor DM, Wolfe RE. Comparation of a suprasternal cardiac output monitor (USCOM) with the pulmonary artery catheter. Br J Anaesth. 2009;103:800-804. doi: 10.1093/ bja/aep296.

132. Pulmonary Artery Consensus Conference: consensus statement. Crit Care Med. 1997;25:910-925.

133. Bishop MH. Invasive monitoring in trauma and other critical illness. Current Opinion in Critical Care 1995;3:206.

134. Magder S. Invasive hemodynamic monitoring. Crit Care Clin. 2015;31:67-87. doi: 10.1016/j.ccc.2014.08.004.

135. De Backer D. Is there a role for invasive hemodynamic monitoring in acute heart failure management? Curr Heart Fail Rep. 2015;12:197-204. doi: 10.1007/s11897-015-0256-6.
136. Runciman WB, Ilsley AH, Roberts JG. An evaluation of thermodilution cardiac output measurement using the SwanGanz catheter. Anaesth Intensive Care. 1981;9:208-220.

137. Ameloot K, Meex I, Genbrugge C, et al. Accuracy of continuous thermodilution cardiac output monitoring by pulmonary artery catheter during therapeutic hypothermia in postcardiac arrest patients. Resuscitation. 2014;85:1263-1268. doi: 10.1016/j.resuscitation.2014.06.025.

138. Mebazaa A, Gheoghiade M, Piña IL, et al. Practical recommendations for prehospital and early in $\neg$ hospital management of patients presenting with acute heart failure SNVSndromes. Crit Care Med. 2008;36(1 Suppl):S129-S139. doi: 10.1097/01.CCM.0000296274.51933.4C.

139. Filipescu D, Tomescu D, Droc G, et al. Recomandări pentru monitorizarea hemodinamică în soc. In: Sandesc D, Bedreag O (eds), Recomandări si protocoale în anestezie, terapie intensivă și medicină de urgentă. Timișoara: Ed Mirton, 2009; p. 541-570.

140. Weed HG. Pulmonary "capillary" wedge pressure not the pressure in the pulmonary capillaries. Chest. 1991;100:11381140.

141. Ryan JJ, Rich JD, Thiruvoipati T, Swamy R, Kim GH, Rich S. Current practice for determining pulmonary capillary wedge pressure predisposes to serious errors in the classification of patients with pulmonary hypertension. Am Heart J. 2012;163:589-594. doi: 10.1016/j.ahj.2012.01.024.

142. Cecconi M, Rhodes A, Della Rocca G. From arterial pressures to cardiac output. JL Vincent (ed), 2008 Yearbook of intensive care and emergency medicine. Berlin: Springer Verlag, 2008; p. 591-600. 